\title{
New developments in the clinical use of drug-coated balloon catheters in peripheral arterial disease
}

This article was published in the following Dove Press journal:

Medical Devices: Evidence and Research

28 June 2016

Number of times this article has been viewed

\author{
Jesse Naghi \\ Ethan A Yalvac \\ Ali Pourdjabbar \\ Lawrence Ang \\ John Bahadorani \\ Ryan R Reeves \\ Ehtisham Mahmud \\ Mitul Patel
}

Division of Cardiovascular Medicine, Sulpizio Cardiovascular Center, University of California, San Diego, CA, USA
Correspondence: Mitul Patel

Division of Cardiovascular Medicine,

Sulpizio Cardiovascular Center,

University of California, San Diego,

9444 Medical Center Drive, La Jolla,

CA 92037, USA

$\mathrm{Tel}+\mathrm{I} 8586575372$

Fax + I 8586575028

Email mpatel@ucsd.edu
Abstract: Peripheral arterial disease (PAD) involving the lower extremity is a major source of morbidity and mortality. Clinical manifestations of PAD span the spectrum from lifestyle limiting claudication to ulceration and gangrene leading to amputation. Advancements including balloon angioplasty, self-expanding stents, drug-eluting stents, and atherectomy have resulted in high technical success rates for endovascular therapy in patients with PAD. However, these advances have been limited by somewhat high rates of clinical restenosis and clinically driven target lesion revascularization. The recent introduction of drug-coated balloon technology shows promise in limiting neointimal hyperplasia induced by vascular injury after endovascular therapies. This review summarizes the contemporary clinical data in the emerging area of drug-coated balloons. Keywords: drug-coated balloons, endovascular, percutaneous transluminal angioplasty, paclitaxel, peripheral arterial disease

\section{Introduction}

Peripheral arterial disease (PAD) of the lower extremity is a major source of morbidity and mortality. Historically, bypass surgery has been the primary method of revascularization for symptomatic patients; however, improvements in efficacy and safety of catheter-based, endovascular interventions have led to a transition to the latter approach becoming the first-line therapy in a variety of anatomic and pathologic scenarios. ${ }^{1}$ The contemporary strategies available for treatment of disease involving the femoropopliteal axis include percutaneous transluminal angioplasty (PTA), atherectomy, and stent implantation. Despite a high initial success rate of up to $95 \%$, each of these options has been limited by unfortunately high rates of vessel restenosis, which ranges from $40 \%$ to $60 \%$ in standard PTA and $25 \%$ to $40 \%$ in stent procedures over 12 months. ${ }^{2-12}$ Limited data regarding implantation of a paclitaxel-eluting nitinol stent have suggested a benefit in terms of restenosis rates. ${ }^{13-17}$ Despite this, the concern for stent fracture, although rare, related to dynamic flexion and torsion in the femoropopliteal axis and resultant in-stent restenosis, which can be more challenging to treat, remains a limitation. ${ }^{9,18,19}$ Thus, an ideal strategy would allow for the deposition of efficacious drug without the need for implantation of a stent platform.

Recently, paclitaxel drug-coated balloons (DCBs) have been developed as a method of homogenous deposition of antiproliferative drug within arteries. When utilized with a carrier molecule, paclitaxel is able to coat a standard angioplasty balloon and is delivered locally to the vessel wall where it remains active for 180 days in order to 
limit restenosis. ${ }^{20}$ Multiple trials have been conducted evaluating the safety, feasibility, and efficacy of these new devices in the treatment of both above-the-knee and below-the-knee (BTK) de novo atherosclerotic lesions. These studies are presented in this review.

\section{Femoropopliteal lesions}

De novo atherosclerosis of the femoropopliteal axis is highly prevalent and contributes to both patient morbidity and health care economic strain. ${ }^{21-23}$ Durable endovascular therapy is evolving to improve long-term outcomes and minimize the need for repeat interventions or amputation. The use of DCBs has been studied and appears to provide effective therapy, which is durable, safe, and technically feasible.

The initial trial comparing DCBs to standard PTA was the THUNDER trial. ${ }^{24}$ This was a multicenter study, which included 154 patients with symptomatic PAD and $\geq 1$ lesions with $\geq 70 \%$ diameter stenosis in the superficial femoral artery (SFA) or popliteal artery treated between 2004 and 2005. Patients were prospectively randomized to one of three strategies, which were DCB angioplasty with a paclitaxelcoated (PACCOCATH $3 \mu \mathrm{g} / \mathrm{mm}^{2}$ paclitaxel coating; Braun Melsungen AG, Berlin, Germany) balloon, standard balloon angioplasty (PTA), and standard balloon angioplasty with the use of paclitaxel solution added to the contrast media (P-Contrast). Baseline characteristics were similar between the three groups (Table 1). Importantly, mean Rutherford classification (RC) (DCB 3.4 \pm 0.8 vs PTA $3.1 \pm 0.8$ vs P-Contrast $3.4 \pm 1, P=0.71$ ), number of totally occluded vessels (DCB $27 \%$ vs PTA $26 \%$ vs P-Contrast $27 \%, P=1$ ), and lesion length (DCB 7.5 $\pm 6.2 \mathrm{~cm}$ vs PTA $7.4 \pm 6.7 \mathrm{~cm}$ vs P-Contrast $7.4 \pm 6.5 \mathrm{~cm}, P=0.73)$ were similar. Angioplasty was performed per standard protocol and technically successful in all patients. Repeat angiography was performed at 6 months, and clinical follow-up was conducted at 6, 12, and 24 months. Clinically, all three groups saw functional improvement as evidenced by 6 -month RC (DCB $3.4 \pm 0.8$ to $1.1 \pm 1.2$ vs PTA $3.1 \pm 0.8$ to $1.2 \pm 1.5$ vs $P$-Contrast $3.4 \pm 1.0$ to $1.7 \pm 1.8, P=0.15$ ). Late lumen loss (LLL) at 6 months (DCB $0.4 \pm 1.2 \mathrm{~mm}$ vs PTA $1.7 \pm 1.8 \mathrm{~mm}$ vs $\mathrm{P}$-Contrast $2.2 \pm 1.6 \mathrm{~mm}, P<0.001)$ and clinically driven target lesion revascularization (CD-TLR) at 6,12 , and 24 months (DCB 4\%/10\%/15\% vs PTA 37\%/48\%/52\% vs P-Contrast $29 \% / 35 \% / 40 \%, P<0.001)$ were significantly lower in the DCB group (Table 2). There were no procedural adverse events attributed to the use of DCB and no difference in the rates of target vessel leg amputation or death between the groups. Long-term follow-up was conducted at 5 years in the DCB and PTA groups, which showed that CD-TLR rates remained significantly lower in the DCB group $(21 \%$ vs $56 \%, P=0.0005) .{ }^{25}$ Binary restenosis (BR) was assessed in a small portion of the study population $(n=31)$ by duplex ultrasound or angiography during this time period and was reported to occur less frequently in the DCB group (17\% vs $54 \%, P=0.04)$. This initial trial showed in a relatively small cohort that application of paclitaxel to a standard angioplasty balloon could improve restenosis rates as assessed by LLL and CD-TLR up to 2 years post-PTA without compromising procedural safety. Long-term follow-up continued to identify benefit among the DCB-treated group.

A similar trial was conducted by Werk et al, ${ }^{26}$ which evaluated 87 patients with symptomatic femoropopliteal disease. Patients were randomized to treatment with standard versus paclitaxel-coated $\left(3 \mu \mathrm{g} / \mathrm{mm}^{2}\right)$ balloon angioplasty. The primary end point was LLL determined at 6 months by angiography, and the secondary end points were target lesion revascularization (TLR), lesion restenosis, and change in ankle-brachial index (ABI). No significant differences were found in baseline or angiographic characteristics between the two groups. Technical success was obtained in all patients with similar number of stents required in $14 \%$ versus $9 \%$ of standard balloon and DCB patients, respectively. LLL $(0.5 \pm 1.1 \mathrm{~mm}$ vs $1.0 \pm 1.1 \mathrm{~mm}, P=0.03)$ and TLR $(2.2 \%$ vs $33 \%, P=0.002$ ) were significantly lower in the DCB group. RC was improved to a greater degree in the DCB group versus standard balloon angioplasty, while follow-up ABI did not differ between the groups. This pilot trial further supported the use of paclitaxel-coated balloons for the treatment of femoropopliteal disease. ${ }^{26}$

The LEVANT 1 (Lutonix paclitaxel-coated balloon for the prevention of femoropopliteal restenosis) trial was a multicenter study, conducted in 2009, of 101 symptomatic patients with $\geq 1$ lesions in the SFA or popliteal artery with $\geq 70 \%$ diameter stenosis and lesions $4-15 \mathrm{~cm}$ in length. ${ }^{27}$ All patients underwent predilation with a standard balloon per institutional protocol. They were then categorized as balloon only or stent cohorts based on the presence of $\geq 70 \%$ residual stenosis or flow-limiting dissection. Each group of patients was then randomized to DCB (Lutonix $2 \mu \mathrm{g} / \mathrm{mm}^{2}$ paclitaxel coating with polysorbate/sorbitol carrier; BARD PV, Tempe, AZ, USA) or PTA in a 1:1 fashion. The primary end point was angiographic 6-month LLL. Secondary outcomes included functional improvement and primary patency (freedom from CD-TLR or BR) at 1, 6, 12, and 24 months. Baseline characteristics were again well-matched and represented real-world cases with the majority of cases having RC 3 (DCB $72 \%$ vs PTA $71 \%, P=0.8$ ), mean lesion length (DCB $80.8 \pm 37 \mathrm{~mm}$ 


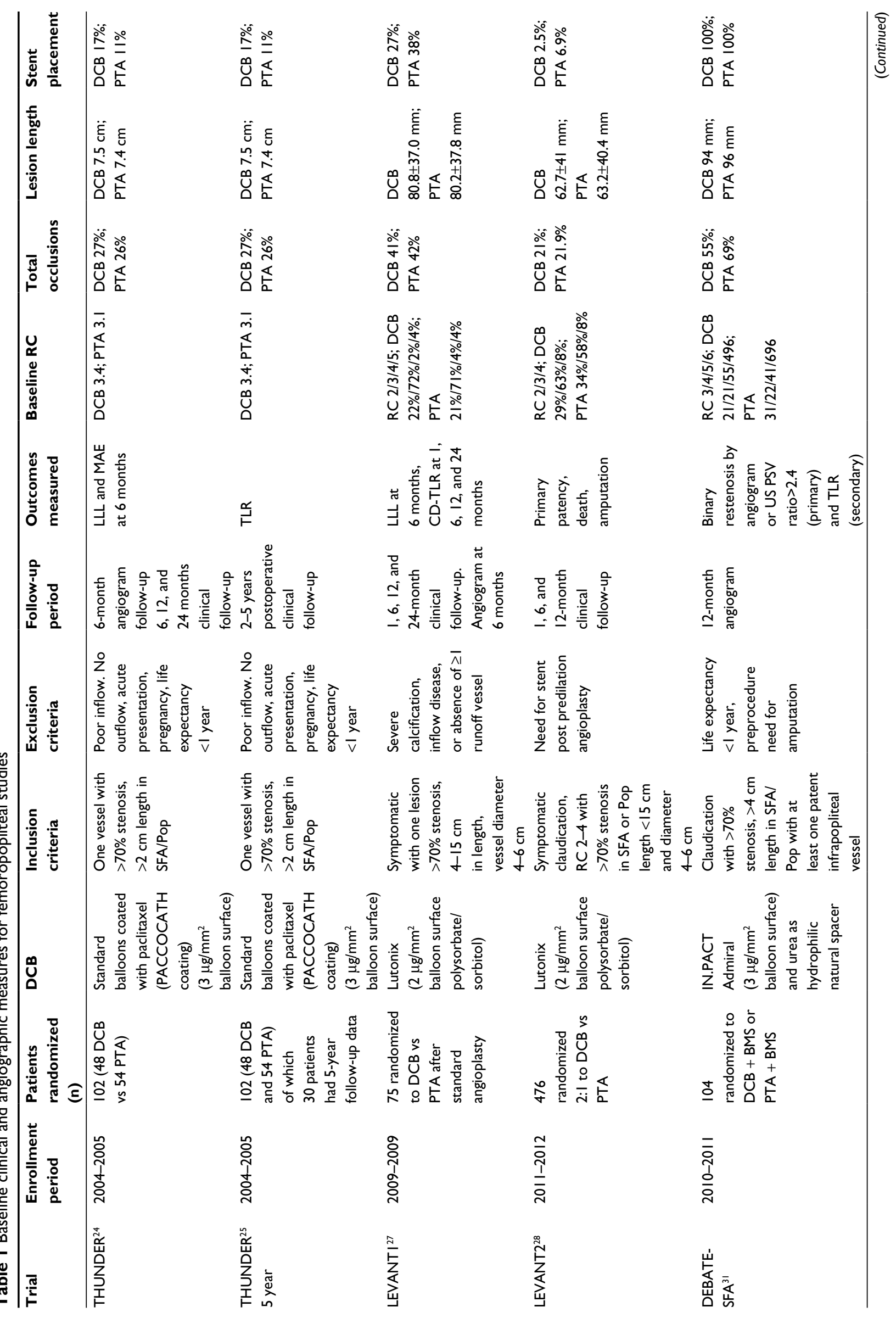




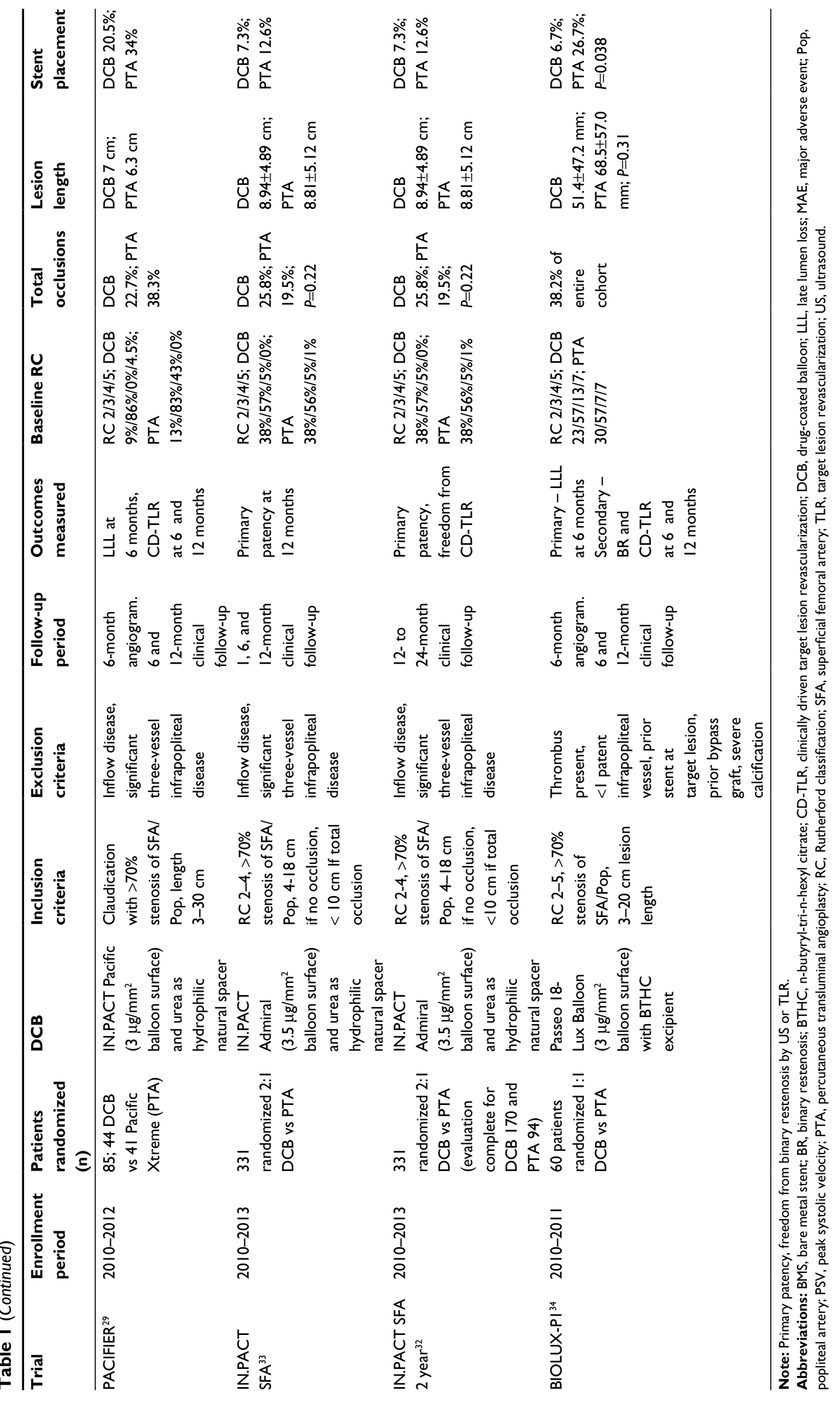


Table 2 Primary and secondary outcomes for femoropopliteal studies

\begin{tabular}{|c|c|c|c|c|c|c|c|}
\hline Trial & $\begin{array}{l}\text { Primary } \\
\text { patency }\end{array}$ & LLL & $\begin{array}{l}\text { RC } \\
\text { improvement } \\
\text { at follow-up }\end{array}$ & ABI change & BR & TLR & MAE \\
\hline THUNDER ${ }^{24}$ & NA & 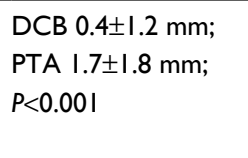 & $\begin{array}{l}\text { DCB I.2; PTA } \\
\text { I.6; } P=0.92\end{array}$ & $\begin{array}{l}\text { DCB 0.9; PTA } \\
0.8 ; P=0.79\end{array}$ & $\begin{array}{l}\text { DCB I7\%; PTA } \\
44 \% ; P=0.01\end{array}$ & $\begin{array}{l}\text { I2/24 months; } \\
\text { DCB I0\%/I5\%; } \\
\text { PTA 48\%/52\%; } \\
\text { P<0.00I/0.00I }\end{array}$ & None \\
\hline $\begin{array}{l}\text { THUNDER } \\
5 \text { years }^{25}\end{array}$ & NA & 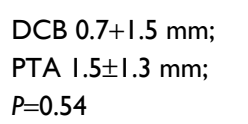 & NA & NA & $\begin{array}{l}\text { DCB I } 7 \% ; \text { PTA } \\
54 \% ; P=0.04\end{array}$ & $\begin{array}{l}\text { DCB 21\%; } \\
\text { PTA 56\%; } P<0.0005\end{array}$ & None \\
\hline LEVANTI ${ }^{27}$ & NA & $\begin{array}{l}\text { DCB } 0.46 \mathrm{~mm} ; \text { PTA } \\
\mathrm{I} .09 \mathrm{~mm} ; P=0.016\end{array}$ & $\begin{array}{l}\text { 6/I 2/24 months; } \\
\text { DCB I.7/I.6/2.I; } \\
\text { PTA I.6/2.1/I.8 }\end{array}$ & $\begin{array}{l}6 / 12 / 24 \text { months; } \\
\text { DCB } \\
0.2 / 0.18 / 0.2 ; \text { PTA } \\
0.22 / 0.2 / 0.18\end{array}$ & NA & $\begin{array}{l}6 / 12 / 24 \text { months; } \\
\text { DCB I3\%/29\%/36\%; } \\
\text { PTA } 24 \% / 37 \% / 51 \% ; \\
P=0.23\end{array}$ & $\begin{array}{l}\text { No difference } \\
\text { between groups }\end{array}$ \\
\hline LEVANT $2^{28}$ & $\begin{array}{l}\text { DCB 65.2\%; } \\
\text { PTA 52.6\%; } \\
P=0.02\end{array}$ & NA & $\begin{array}{l}12 \text { months; DCB } \\
\text { I.9; PTA I.7; } \\
\text { P=NS }\end{array}$ & $\begin{array}{l}12 \text { months; DCB } \\
0.17 ; \text { PTA } 0.18 ; \\
P=N S\end{array}$ & $\begin{array}{l}\text { DCB 62\%; PTA } \\
65 \% ; P=N S\end{array}$ & $\begin{array}{l}\text { I } 2 \text { months; } \\
\text { DCB 38\%; } \\
\text { PTA } 37.5 \% ; P=N S\end{array}$ & $\begin{array}{l}\text { DCB } 16 \% ; \\
\text { PTA } 21 \% ; P=N S\end{array}$ \\
\hline $\begin{array}{l}\text { DEBATE- } \\
\text { SFA }^{31}\end{array}$ & NA & $\begin{array}{l}\text { DCB } 0.86 \mathrm{~mm} ; \text { PTA } \\
\mathrm{I} .68 \mathrm{~mm} ; P<0.00 \mathrm{I}\end{array}$ & $\begin{array}{l}\text { RC delta } \geq 2 ; \\
\text { DCB 8I.8\%; PTA } \\
54.5 \% ; P=0.02\end{array}$ & NA & $\begin{array}{l}\text { DCB I7\%; PTA } \\
47.3 \% ; P=0.008\end{array}$ & $\begin{array}{l}12 \text { months; DCB } \\
\text { I } 7 \% \text {; PTA 33.3\%; } \\
P=0.07\end{array}$ & None \\
\hline PACIFIER $^{29}$ & NA & $\begin{array}{l}\text { DCB }-0.01 \mathrm{~mm} ; \\
\text { PTA } 0.65 \mathrm{~mm} ; \\
P=0.001\end{array}$ & $\begin{array}{l}\text { Improvement } \\
\text { in RC >I; DCB } \\
80 \% \text {; PTA } 68 \%\end{array}$ & NA & $\begin{array}{l}\text { DCB 8.6\%; PTA } \\
32.4 \% ; P=0.01\end{array}$ & $\begin{array}{l}6 / 12 \text { months; } \\
\text { DCB } 7.1 \% / 7.1 \% ; \\
\text { PTA } 26.2 \% / 34.9 \% ; \\
P=0.01 / 0.01\end{array}$ & $\begin{array}{l}\text { Death, amputation, } \\
\text { TLR; DCB 7.I\%; } \\
\text { PTA } 34.9 \% ; \\
\text { P=0.003 }\end{array}$ \\
\hline $\begin{array}{l}\text { IN.PACT } \\
\text { SFA }^{33}\end{array}$ & $\begin{array}{l}\text { DCB } 82.2 \% \\
\text { PTA 52.4\%; } \\
P<0.001\end{array}$ & NA & $\begin{array}{l}\text { Sustained clinical } \\
\text { improvement; } \\
\text { DCB 85\%; PTA } \\
67 \% ; P<0.00 \text { I }\end{array}$ & $\begin{array}{l}\text { DCB 0.95; PTA } \\
0.89 ; P=0.002\end{array}$ & NA & $\begin{array}{l}\text { DCB } 2.4 \% \\
\text { PTA 20.6\%; } \\
P<0.00 \text { I }\end{array}$ & No difference \\
\hline $\begin{array}{l}\text { IN.PACT } \\
\text { SFA } 2 \text { years }^{32}\end{array}$ & $\begin{array}{l}\text { DCB } 78.9 \% ; \\
\text { PTA 50.1\%; } \\
P<0.001\end{array}$ & NA & $\begin{array}{l}\text { Sustained clinical } \\
\text { improvement; } \\
\text { DCB 77\%; PTA } \\
59 \% ; P=0.003\end{array}$ & $\begin{array}{l}\text { DCB 0.92; PTA } \\
0.94 ; P=0.6 \mathrm{II}\end{array}$ & $\begin{array}{l}\text { DCB 19.8\%; } \\
\text { PTA 46.9\%; } \\
P<0.01\end{array}$ & $\begin{array}{l}\text { DCB 9.1\%; } \\
\text { PTA 28.3\%; } \\
P<0.001\end{array}$ & $\begin{array}{l}\text { Safety composite: } \\
\text { DCB 87.4\%; PTA } \\
69.4 \% ; P<0.001 ; \\
\text { MAE: DCB I9.2\%; } \\
\text { PTA 3I.I\%; } P=0.02\end{array}$ \\
\hline BIOLUX-PI ${ }^{34}$ & NA & $\begin{array}{l}\text { DCB } 0.5 \mathrm{I} \pm 0.72 \mathrm{~mm} \text {; } \\
\text { PTA I.04 } \pm \mathrm{I} .00 \mathrm{~mm} \\
P=0.033\end{array}$ & $\begin{array}{l}\text { RC improvement } \\
\text { >I; DCB } 72 \% ; \\
\text { PTA } 65.2 \% ; P=N S\end{array}$ & $\begin{array}{l}\text { DCB } 0.9 \pm 0.2 ; \\
\text { PTA 1.0 } 0 \pm 0.2\end{array}$ & $\begin{array}{l}\text { DCB II.5\%; } \\
\text { PTA } 34.6 \% ; \\
P=0.048\end{array}$ & $\begin{array}{l}\text { DCB 15.4\%; } \\
\text { PTA 41.7\%; } P=0.06\end{array}$ & $\begin{array}{l}\text { DCB 19.2\%; } \\
\text { PTA 41.2\%; } P=0.14\end{array}$ \\
\hline
\end{tabular}

Note: Primary patency, freedom from binary restenosis by US or TLR.

Abbreviations: $A B I$, ankle-brachial index; BR, binary restenosis; DCB, drug-coated balloon; LLL, late lumen loss; MAE, major adverse event; NA, not available; NS, not significant; PTA, percutaneous transluminal angioplasty; RC, Rutherford classification; SFA, superficial femoral artery; TLR, target lesion revascularization; US, ultrasound.

vs PTA $80.2 \pm 37.8 \mathrm{~mm}, P=0.89)$, and total occlusion rate (DCB $41 \%$ vs PTA $42 \%, P=0.88$ ) (Table 1). Device success was notably lower in the DCB group compared with PTA, as there were eight device malfunctions, which resulted in an inability to deposit adequate drug at the lesion site. This device-related issue was related to twisted folds in the balloon itself, which prevented inflation and was corrected early on in the trial with no further malfunctions noted. Despite the lower technical success rate, LLL at 6 months was significantly lower in the DCB group (DCB $0.46 \pm 1.13 \mathrm{~mm}$ vs PTA $1.09 \pm 1.07 \mathrm{~mm}, P=0.016$ ). Primary patency (DCB 57\% vs PTA $40 \%, P>0.05$ ) and CD-TLR (DCB 36\% vs PTA 49\%, $P>0.05)$ at 24 months were similar between the two groups. $\mathrm{ABI}$ and $\mathrm{RC}$ were notably improved from baseline in both the groups to 24 months. Composite major adverse events (MAEs) (death, thrombosis, amputation, reintervention) occurred in $39 \%$ of the DCB cohort and $46 \%$ of the PTA cohort ( $P=0.45$ ) (Table 2$)$. In the LEVANT 1 trial, long-term clinical equipoise was noted between the Lutonix DCB and standard balloon angioplasty despite a significant difference observed in LLL. This result may have been influenced by the early occurrence of device malfunction as freedom from CD-TLR, and primary patency rates between the successful and failed DCB patients were significantly lower. Further studies evaluating the Lutonix DCB were recommended.

Based on the results from the LEVANT 1 trial, the Lutonix balloon was further evaluated in a large multicenter setting. ${ }^{28}$ The LEVANT 2 trial enrolled 543 patients with 
symptomatic claudication and $\geq 1$ lesions in the SFA or popliteal artery of $\geq 70 \%$ diameter stenosis in a $4-6 \mathrm{~mm}$ vessel with a total length of $<15 \mathrm{~cm}$. All patients in this trial underwent lesion predilation with a standard balloon, and if no need for stenting (ie, flow-limiting dissection or residual stenosis $>70 \%$ ) was found, they were randomized in a 2:1 fashion to DCB with the Lutonix balloon or PTA. Four hundred and seventy-six patients were randomized to DCB versus PTA with respective procedural success rates of $88.9 \%$ and $86.8 \%, P=0.5$. Baseline characteristics were well-matched, and percent RC 3 (62.7\% vs 57.5\%), lesion length $(62.7 \pm 41.4 \mathrm{~mm}$ vs $63.2 \pm 40.4 \mathrm{~mm})$, and total occlusions $(20.6 \%$ vs $21.9 \%)$ were similar between the DCB and PTA groups (Table 1). Primary patency was evaluated at 12 months and was found to be significantly better in the DCB group (65.2\% vs 52.6\%, $P=0.02)$. CD-TLR occurred at similar rates between the DCB and PTA groups $(12.3 \%$ vs $16.8 \%, P=0.21)$. The primary safety measure was a composite of freedom from perioperative death and freedom at 12 months from index limb amputation, index limb revascularization, and index limb-related amputation occurred at similar rates between the groups ( $83.9 \%$ vs $79.0 \%)$, and the DCB met noninferiority criterion with regard to safety (Table 2). The LEVANT 2 trial showed promising results in terms of safety and efficacy in terms of primary patency at 1-year follow-up. Despite this, rates of CD-TLR remained similar between the two groups. This may be related to an unexpectedly lower rate of CD-TLR in the PTA group than previous studies, and long-term follow-up is underway to further evaluate this cohort.

Based on the data from the initial THUNDER trial, a similar paclitaxel-coated balloon was developed with the use of urea as the carrier molecule to enhance homogenous delivery $\left(\right.$ FreePac $^{\circledR}$; Medtronic, Santa Rosa, CA, USA). The first balloon evaluated with this new coating was studied in the PACIFIER trial. ${ }^{29}$ Subjects were enrolled if they had RC 2-5 and $\geq 1$ lesions in the SFA or popliteal artery with $\geq 70 \%$ diameter stenosis, which was $3-30 \mathrm{~cm}$ in length. Randomization was performed in 85 patients who met criteria after successful wiring of the lesion in a 1:1 fashion to DCB (IN.PACT Pacific paclitaxel-coated $3 \mu \mathrm{g} / \mathrm{mm}^{2}$ balloon; Medtronic) or PTA (Pacific Xtreme balloon; Medtronic). Of note, only 13.6\% of patients underwent predilation with a standard balloon in the DCB group. Clinically, the DCB and PTA groups were similar with regard to RC 3 (86.4\% vs $83 \%)$, lesion length ( $70 \pm 53 \mathrm{~mm}$ vs $66 \pm 55 \mathrm{~mm})$, and total occlusions $(22.7 \%$ vs $38.3 \%$ ), respectively (Table 1 ). The primary efficacy end point of mean LLL at 6 months was significantly better in the DCB group $(-0.01 \mathrm{~mm}$ vs $0.65 \mathrm{~mm}, P=0.001)$. Interestingly, the authors reported that lesions with larger degree residual stenosis post DCB were more likely to see lower LLL or even positive remodeling, which they speculated to be secondary to the antiproliferative effects of paclitaxel and plaque regression. BR rates were lower in the DCB group at 6 months $(8.6 \%$ vs $32.4 \%, P=0.01)$. Improvement in $\mathrm{RC}$ was observed in numerically but not statistically more of the DCB patients ( $80 \%$ vs $68.4 \%, P=0.36$ ). MAE (death, amputation, or CD-TLR) at 12 months was significantly lower in the DCB group $(7.1 \%$ vs $34.9 \%, P=0.003)$, which was largely driven by less CD-TLR ( $7.1 \%$ vs $27.9 \%, P=0.02$ ) (Table 2 ). The PACIFIER trial showed excellent efficacy and safety rates for the novel paclitaxel-coated IN.PACT balloon and interestingly a mean LLL, which suggested positive remodeling of the vessel after DCB.

While the use of PTA is generally the first strategy for the treatment of the femoropoliteal axis, stent deployment is frequently necessary in complex lesions. Restenosis rates remain high with bare metal stents (BMSs) and are ameliorated with drug-eluting stents (DESs). ${ }^{14,30}$ These findings have raised the question as to whether it is the drug itself, the polymer, or the scaffold that is responsible for improvement in long-term results. To further evaluate the effect of DCBs in the setting of complex femoropopliteal lesions with a planned bare metal nitinol stent (Maris stent, Invatec; Medtronic) implantation strategy, the DEBATE-SFA trial was conducted. ${ }^{31}$ This trial randomized 104 patients with symptomatic PAD (claudication and critical limb ischemia [CLI]) and complex lesions (lesion length DCB 94 $\pm 60 \mathrm{~mm}$ vs PTA $96 \pm 69 \mathrm{~mm}, P=0.5$; total occlusions DCB $54.5 \%$ vs PTA $69.1 \%, P=0.1$; severe calcification DCB $22 \%$ vs PTA $20 \%, P=0.8$ ) to DCB+BMS (IN.PACT Admiral Balloon) or PTA+BMS in a 1:1 fashion (Table 1). Technical and procedural success was $100 \%$ in both groups. Patients were evaluated at 12 months either angiographically or by Doppler ultrasound (DUS) for BR, which was significantly lower in the DCB + BMS patients (7.3\% vs $17 \%, P=0.008)$. This finding held true even among patients with very long lesions ( $\geq 100 \mathrm{~mm})(21 \%$ vs $62 \%, P=0.01)$ and patients who achieved recanalization via a subintimal dissection and reentry approach $(0 \%$ vs $47.1 \%, P=0.01)$. The secondary end point of freedom from CD-TLR at 12 months trended toward benefit in the DCB + BMS group (DCB 83\% vs PTA $66.7 \%, P=0.07)$. Of the patients evaluated by angiography, LLL at 12 months was significantly lower in the DCB group ( $0.86 \mathrm{~mm}$ vs $1.68 \mathrm{~mm}, P<0.001)$. Additionally, RC improvement $\geq 2$ was observed more often in the DCB group 
( $81.8 \%$ vs $54.5 \%, P=0.02)$ (Table 2 ). This trial demonstrates that predilation with a DCB in complex lesions with planned BMS implantation results in lower rates of LLL and BR at 1 year follow-up with a trend toward lower CD-TLR.

Further evaluation of the IN.PACT Admiral balloon (paclitaxel dose $3.5 \mu \mathrm{g} / \mathrm{mm}^{2}$ balloon surface) was conducted in the larger multicenter trial, IN.PACT SFA, which randomized 331 patients from 2010 to 2013 with symptomatic femoropoliteal disease to DCB or PTA in a 2:1 fashion. Primary patency, defined as freedom from CD-TLR or restenosis evidence on DUS, was evaluated at 12 months and then at 24 months. Lesion length (DCB $89.4 \pm 49 \mathrm{~mm}$ vs PTA $88.1 \pm 51.2 \mathrm{~mm}$ ), total occlusions (DCB $25.8 \%$ vs PTA $19.5 \%$ ), and RC 3 (DCB 57\% vs PTA 56\%) were similar between the groups (Table 1). Procedural success was achieved in $99.5 \%$ and $98.2 \%$ of DCB and PTA patients, respectively. Of note, predilation was performed more frequently in the DCB arm as compared to the standard PTA arm (96\% vs $86 \%$ ). Primary patency was significantly higher in the DCB group at 12 months $(82.2 \%$ vs $52.4 \%$, $P<0.001)$ and 24 months $(78.9 \%$ vs $50.1 \%, P<0.001)$. Impressively, 12 -month CD-TLR was only $2.4 \%$ in the DCB group vs $20.6 \%, P<0.001$, which remained significant at 24 months follow-up $(9.1 \%$ vs $28.3 \%, P<0.001) .{ }^{32,33}$ Functional improvement was observed in both groups at 12 and 24 months, although the DCB group achieved this with 58\% fewer reinterventions (Table 2). There were no procedurerelated deaths or amputations noted in either group. Past trials evaluating DCBs were relatively small in size and showed mainly significant benefit based on angiographic measures of restenosis (ie, LLL). However, this large, multicenter trial was able to demonstrate superiority of the IN.PACT Admiral DCB when compared to PTA in terms of clinical events at up to 24 months follow-up.

Recently, novel DCBs have been developed and tested in small trials for safety and efficacy. The BIOLUX-P1 trial was the first in human trial to evaluate the Passeo-18 Lux DCB ( $3 \mu \mathrm{g}$ of paclitaxel $/ \mathrm{mm}^{2}$ ), which is coated with paclitaxel using n-butyryl-tri-n-hexyl citrate (BTHC) (Biotronik AG, Buelach, Switzerland). ${ }^{34}$ This group randomized 60 patients with symptomatic femoropopliteal arterial disease in a 1:1 fashion to treatment with the Passeo-18 Lux balloon or standard PTA. The primary end point was LLL at 6 months. Secondary end points were BR at 6 months, CDTLR, change in $A B I$ and RC, and MAEs at 6 and 12 months. At 6 months, patients treated in the DCB group had a significantly lower LLL $(0.51 \pm 0.72 \mathrm{~mm}$ vs $1.04 \pm 1.00 \mathrm{~mm}$, $P=0.033)$ and $\mathrm{BR}(11.5 \%$ vs $34.6 \%, P=0.048)$ than the PTA group. Additionally, there was a reduction in CD-TLR in the DCB group at 12 months $(15.4 \%$ vs $41.7 \%$ [ $P=0.064]$ for the intention-to-treat population and $16.0 \%$ vs $52.9 \%$ $[P=0.020]$ for the as-treated population). No death and one minor amputation were observed compared with two deaths and two minor amputations in the control group. No major amputations or thrombosis were reported. Similarly, the novel low drug dose Stellarex DCB $\left(2 \mu \mathrm{g} / \mathrm{mm}^{2}\right.$ balloon surface and polyethylene glycol excipient) was evaluated in a prospective single-arm trial for safety and efficacy. ${ }^{35}$ In the Illumenate trial, 50 patients with 58 lesions were enrolled and treated with standard PTA followed by DCB with the Stellarex balloon. The primary effectiveness end point was 6-month LLL. The major secondary end point was MAE rate at 6 months, defined as cardiovascular death, amputation, and/or ischemia-driven TLR. Clinical followup and Doppler ultrasonography were performed up to 24 months postprocedurally. The primary and secondary end points met their prespecified goals at 6 months, as the MAE rate was $4 \%$ and the mean LLL was $0.54 \mathrm{~mm}$. The primary patency rate was $89.5 \%$ at 12 months and $80.3 \%$ at 24 months. The freedom from CD-TLR was $90.0 \%$ at 12 months and $85.8 \%$ at 24 months. Additionally, there were no amputations or cardiovascular deaths reported through 24 months. These studies are encouraging as they highlight the efficacy and safety of newer generation DCBs on the horizon.

These trials support the efficacy of DCBs across the spectrum of patients with symptomatic femoropopliteal PAD. Both angiographic and clinical outcomes are markedly improved with utilization of DCB with rates of primary patency ranging from $65 \%$ to $90 \%$ at 1 year. Although the Lutonix balloon shows significant improvement in primary patency, CD-TLR was similar compared with PTA, which may be related to the choice of drug excipient. The IN.PACT Admiral balloon has shown excellent rates of CD-TLR at both 1 year and 2 years, which can reduce the long-term need for reintervention while providing functional improvement. MAEs did not differ significantly between the DCB and PTA groups in any study, supporting the safety of these novel balloons. Finally, it should be noted that the largest and most contemporary trials comparing DCB technology to standard PTA, namely, the INPACT SFA, LEVANT 2, and BIOLUX P-1 trials, were performed with rigorous study designs and validated by core laboratory adjudication..$^{28,33,34}$ Additional subsets of patients have been studied in numerous trials, including patients with in-stent restenosis and BTK disease, and these studies are discussed later. 


\section{Infrapopliteal disease and CLI}

CLI is the salient clinical stage of progressive PAD and often an earmark of broader systemic atherosclerosis. Patients present with symptoms of resting claudication, nonhealing ulceration, and if left untreated, gangrene. RC 4-6 are the descriptive surrogates for these three stages and are typically associated with an $\mathrm{ABI}<0.4$. Physiologically, CLI is explained by the mismatch of arterial perfusion and metabolic demand leading to reduced tissue oxygen tension and cellular injury. Nearly half of all untreated CLI patients will require major amputation (defined as above the ankle) within 1 year. ${ }^{36,37}$ Major amputation is associated with reduced quality of life and poor overall survival. ${ }^{38}$ Today, CLI carries an intermediate-term survival (defined as a 1 - to 2-year mortality risk) of $\sim 25 \% .{ }^{39}$ As opposed to significant reductions in mortality with many pathologic processes, mortality from complications of CLI have only mildly diminished over the last 20 years. In 1997, the ICAI Group (Gruppo di Studio dell'Ischemia Cronica Critica degli Arti Inferiori) reported a 31\% 2-year mortality in CLI patients. ${ }^{39}$ A recent multicenter retrospective analysis identified adverse cardiovascular events (eg, myocardial infarction and stroke) as the primary mortality risk (47\%) for CLI patients. ${ }^{40}$ The Bypass versus Angioplasty in Severe Ischemia of the Leg (BASIL) trial randomized CLI patients to either surgery or balloon angioplasty and showed equivalent 12 -month (71\% vs $68 \%$ ) and 36 -month (52\% vs $57 \%$ ) rates of amputationfree survival, despite lower patency in the angioplasty arm. The 2-year mortality in the BASIL trial was $26.8 \% .{ }^{41}$ These findings highlight the conceptual goals of endovascular revascularization in CLI patients. Long-term vessel patency, although desirable, is less frequently achievable and perhaps unnecessary as even short-term improvement in perfusion and tissue oxygenation facilitates wound healing and limb salvage (LS). Once the higher metabolic needs for wound healing are satisfied, the perfusion demands of the limb are mitigated. This concept suggests that the commonly used end points of angiographic success, LLL, primary patency, and BR, are less likely relevant in the tibial vascular bed. Instead, end points highlighting clinical success such as improvement in RC, freedom from bypass, CD-TLR, and LS should be employed.

Given the remarkable efficacy of DCB technology in above-the-knee interventions, it is not surprising there is great interest and hope for its infrapopliteal application..$^{27,32}$ However, there are aspects that are unique to BTK pathology. Other than the obvious smaller vessel lumen, infrapopliteal disease is often complex involving long, diffusely stenotic vessels burdened with heavy calcification. In CLI patients, chronic occlusions of at least one if not multiple tibial vessels are usually encountered. Inflow lesions (proximal to the tibial vessels) and/or poor pedal runoff compound the risk for thrombosis and distal embolization. Determination of procedural success can be difficult with variable and difficult to gauge end points. Traditional PTA has become the initial intervention of choice for CLI. In one cohort (average lesion length $184 \mathrm{~mm}$ ), combined restenosis/occlusion rates at 3 months were reported to be as high as $69 \%$; yet, clinical improvement (improvement in wound healing or RC) was observed in $75.8 \%$. At 15 months, the rate of CD-TLR was $50 \%$; however, LS was an impressive $100 \%{ }^{42}$ Multiple series corroborate long-term PTA LS rates between $75 \%$ and $100 \%$ achieved at the expense of increased CD-TLR..$^{41,43,44}$ Infrapopliteal DCB-facilitated revascularization has been and continues to be studied in the hope of achieving improved outcomes, the need for reintervention and in turn, reduced overall costs. Recent evidence suggests that there may also be a role for infrapopliteal DESs in the management of CLI. ${ }^{45}$ Nonetheless, there is a relative paucity of randomized controlled evidence exploring the optimal use of DESs in this territory, and stents are generally limited to the proximal aspect of the infrapopliteal vessels. As in our above-theknee analysis, this review focuses on de novo infrapopliteal atherosclerotic lesions treated with DCB technology.

\section{DCB versus PTA for infrapopliteal disease}

In 2011, Schmidt et al ${ }^{46}$ published the first single-arm prospective trial using DCB to treat long infrapopliteal lesions. The IN.PACT Amphirion (Medtronic) used the same proprietary FreePac coating as the Medtronic IN.PACT Admiral (lipophilic paclitaxel $3 \mu \mathrm{g} / \mathrm{mm}^{2}$ with a hydrophilic urea excipient). In 104 patients, 109 limbs were treated for CLI $(82.6 \%)$ or severe claudication (17.4\%). Baseline mean RC was 4.5 with $64.2 \%$ of patients classified as RC 5 (Table 3 ). The primary end point was angiographic BR (defined as $50 \%$ diameter reduction) and assessed 3 months after the initial procedure. Clinical outcomes were assessed at 3 months and 12 months after DCB angioplasty. Clinical improvement was defined as $\geq 50 \%$ reduction of ulcer size/depth or an increase of at least one RC. Secondary outcomes included need for major amputation, target vessel revascularization, and bypass surgery. Predilatation with an uncoated balloon and a diameter at least $0.5 \mathrm{~mm}$ smaller than the DCB was performed in all lesions in order to guarantee contact of the DCB and improved drug delivery. DCB inflation time was at 


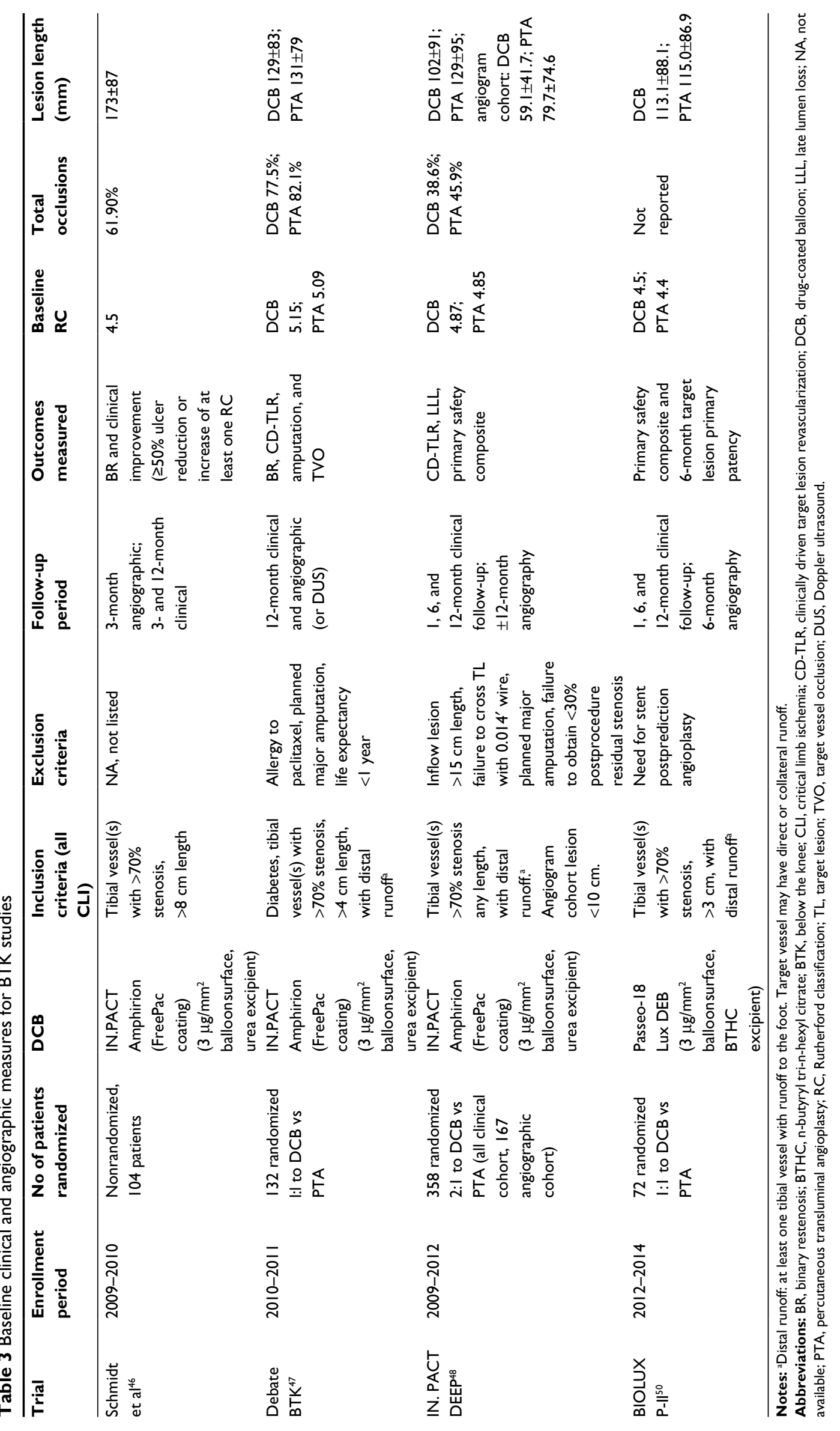


least 1 minute, and in the case of flow-limiting dissection or residual stenosis ( $>30 \%$ ), a prolonged dilation up to 5 minutes was performed. Mean lesion length was $173 \pm 87 \mathrm{~mm}$ with $61.9 \%$ of target lesions described as total occlusions. Five cases required bailout stenting. Three-month angiographic data were collected from 84 arteries in the 79 treated limbs of 74 patients. Angiographic primary patency persisted in 61 of the 84 treated arteries (72.6\%). BR was observed in $27.4 \%$ of treated arteries (19.1\% restenosis and $8.3 \%$ target vessel occlusion). Twelve-month clinical data were drawn from 86 patients with 91 treated limbs. Clinical improvement occurred in $91.2 \%$ of these limbs. TLR was performed in $17.3 \%$, and LS was achieved in $95.6 \%$ of the CLI patients (Table 4). Complete wound healing occurred in $74.2 \%$ of patients with RC 5 classification at baseline. No bypass surgery was performed during the entire study period. There were four unplanned amputations (two minor, two major). A notable observation by the authors was an altered pattern of recurrent disease after DCB therapy. In $60 \%$ of restenotic vessels, lesion length was $<20 \%$ of the original target lesion. They propose that such a pattern of focal restenosis stands in contrast to the experience with uncoated balloons and may have contributed to the impressive clinical outcomes of the study. ${ }^{42}$ Not surprisingly, randomized controlled trials quickly followed on the heels of this pilot study.
Further evaluation of DCB therapy in BTK disease continued with the DEBATE-BTK trial (Drug-Eluting Balloon in Peripheral Intervention for Below the Knee Angioplasty Evaluation). ${ }^{47}$ In this randomized, open-label, single-center study, 132 diabetic patients with 158 infrapopliteal lesions were enrolled to compare DCB angioplasty with traditional PTA. As in the previously mentioned study by Schmidt et al, ${ }^{46}$ the study balloon was the Medtronic IN.PACT Amphirion. Inclusion criteria were diabetes mellitus, CLI $(\mathrm{RC} \geq 4)$, stenosis or occlusion $>40 \mathrm{~mm}$ of at least one BTK vessel with distal runoff, and life expectancy $>1$ year. The primary end point was binary in-segment restenosis at 12 months as assessed by angiography or DUS. Restenosis was defined as $>50 \%$ reduction in luminal diameter by angiography or a peak systolic velocity ratio $>2.5$ by DUS. Secondary end points were CD-TLR, major amputation, and target vessel occlusion. Patient characteristics were statistically well matched. Mean RC at baseline was 5.15 and 5.09 in the DCB and PTA cohorts, respectively. CLI with RC $\geq 5$ was present in $97.2 \%$ of DCB patients and $95.8 \%$ of PTA patients. Mean ABIs at baseline were 0.31 (DCB) and 0.29 (PTA). Standard balloon predilatation was mandatory prior to DCB dilatation. To avoid geographic miss, radiopaque rulers were used to ensure the DCB treatment zone extended $10 \mathrm{~mm}$ beyond the proximal and distal predilatation. Inflation

Table 4 Primary and secondary outcomes for BTK studies

\begin{tabular}{|c|c|c|c|c|c|c|c|}
\hline Trial & $\begin{array}{l}\text { Primary } \\
\text { patency }\end{array}$ & LLL $(\mathrm{mm})$ & BR & $\begin{array}{l}\text { Clinical } \\
\text { improvement or } \\
\mathrm{RC} \text { at follow-up }\end{array}$ & ABI & TLR & MAEs \\
\hline $\begin{array}{l}\text { Schmidt et al }{ }^{46} \\
\text { (Single Center } \\
\text { Leipzig } \\
\text { Registry) }\end{array}$ & $\begin{array}{l}3 \text { months: } \\
72.6 \%\end{array}$ & NA & $\begin{array}{l}27.4 \%: 19.1 \% \\
\text { restenosis } \\
\text { and } 8.3 \% \\
\text { target vessel } \\
\text { occlusion }\end{array}$ & $\begin{array}{l}\text { Clinical } \\
\text { improvement } 91.2 \% \text {, } \\
\text { complete wound } \\
\text { healing } 74.2 \% \text { of RC } \\
5 \text { patients }\end{array}$ & NA & $17.3 \%$ & $\begin{array}{l}\text { Four amputations } \\
\text { (two major, two minor) }\end{array}$ \\
\hline Debate BTK ${ }^{47}$ & NA & NA & $\begin{array}{l}\text { DCB: } 27.0 \% \text {; } \\
\text { PTA: } 74.3 \% \\
(P<0.001)\end{array}$ & $\begin{array}{l}\text { DCB: } 0.90 \pm 1.8 \\
\text { PTA: } 2.0 \pm 2.3 \\
(P<0.004)\end{array}$ & $\begin{array}{l}\text { DCB: } \\
0.78 \pm 0.22 ; \\
\text { PTA: } \\
0.47 \pm 0.28\end{array}$ & $\begin{array}{l}\text { DCB: I8\%; PTA: } \\
\text { 43\% }(P=0.002) ; \\
\text { TVO-DCB: } \\
\text { I7\%; PTA: } 55 \% \\
(P<0.001)\end{array}$ & $\begin{array}{l}\text { DCB: } 31 \% \text {; PTA: } 51 \% \\
(P=0.02)-\text { driven by } \\
\text { TLR and wound healing } \\
\text { amputation-DCB: } 0 \% ; \\
\text { PTA: I.5\% }(P=0.0005)\end{array}$ \\
\hline $\begin{array}{l}\text { IN.PACT } \\
\text { DEEP }{ }^{48}\end{array}$ & NA & $\begin{array}{l}\text { DCB: } \\
0.61 \pm 0.78 \mathrm{~mm} ; \\
\text { PTA: } 0.62 \pm 0.78 \mathrm{~mm} \\
(P=0.950)\end{array}$ & $\begin{array}{l}\text { DCB: } 41.0 \% \text {; } \\
\text { PTA: } 35.5 \% \\
(P=0.609)\end{array}$ & NA & NA & $\begin{array}{l}\text { CD-TLR; DCB: } \\
\text { 9.2\%; PTA: } \\
\text { 13.1\% }(P=0.291)\end{array}$ & $\begin{array}{l}\text { 6-month primary safety } \\
\text { composite - DCB: } \\
\text { I7.7\%; PTA: I5.8\%; } \\
\text { I2-month major } \\
\text { amputation - DCB: } \\
\text { 8.8\%; PTA: } 3.6 \%\end{array}$ \\
\hline BIOLUX P-II & $\begin{array}{l}\text { DCB } 65.2 \% ; \\
\text { POBA 52.6\%; } \\
P=0.02\end{array}$ & $\begin{array}{l}\text { DCB: } \\
0.56 \pm 0.65 \mathrm{~mm} ; \\
\text { PTA: } 0.54 \pm 0.66 \mathrm{~mm} \\
(P=0.913)\end{array}$ & $\begin{array}{l}\text { DCB: } 53.1 \% \text {; } \\
\text { PTA: } 41.4 \% \\
(P=0.359)\end{array}$ & $\begin{array}{l}\text { DCB: } 2.3 \pm 2.3 \text {; PTA: } \\
2.7 \pm 2.4(P>0.05)\end{array}$ & $\begin{array}{l}\text { I2-month } \\
\text { DCB: } 1.0 \pm 0.2 \text {; } \\
\text { PTA: } 0.9 \pm 0.2 \\
(P=0.327)\end{array}$ & $\begin{array}{l}\text { CD-TLR; DCB: } \\
\text { 31.3\%; PTA: } \\
\text { 26.9\% }(P=0.805)\end{array}$ & $\begin{array}{l}\text { I2-month MAE } \\
\text { composite; DCB: } \\
\text { 4I.I\%; PTA: } 39.1 \% \\
(P=0.957)\end{array}$ \\
\hline
\end{tabular}

Abbreviations: $A B I$, ankle-brachial index; BR, binary restenosis; BTK, below-the-knee; CD-TLR, clinically driven target lesion revascularization; DCB, drug-coated balloon; LLL, late lumen loss; MAE, major adverse event; NA, not available; POBA, plain old balloon angioplasty; PTA, percutaneous transluminal angioplasty; RC, Rutherford classification; TLR, target lesion revascularization; TVO, target vessel occlusion. 
time was at least 2 minutes for both DCB and PTA arms. In case of flow-limiting dissection or residual stenosis $>30 \%$, prolonged dilatation up to 3 minutes was performed. Lesion characteristics and complexity were statistically well matched (Table 3). Average lesion length was $129 \pm 83 \mathrm{~mm}$ (DCB) and $131 \pm 79 \mathrm{~mm}$ (PTA). In both groups, $\sim 80 \%$ of lesions were total occlusions and $25 \%$ were heavily calcified. Subintimal recanalization techniques were utilized in $20 \%$ of patients in both study arms, and $\sim 50 \%$ of patients underwent inflow lesion treatment during the index procedure. Of the 124 patients alive at 12 months, angiograms were available for 67 of $74(91 \%)$ and 68 of $74(92 \%)$ eligible lesions in the DCB and PTA arms, respectively. The primary end point, 12-month BR, occurred in 20 (27\%) and 55 (75\%) lesions in the DCB and PTA groups, respectively $(P<0.001)$. Target vessel occlusion with DCB occurred in 13 (17\%) versus $41(55 \% ; P<0.001)$ lesions in the standard PTA group. As anecdotally noted by Schmidt et al, ${ }^{46}$ occlusion lengths were found to be significantly shorter in the DCB cohort compared to PTA, $87 \pm 88 \mathrm{~mm}$ versus $128 \pm 75 \mathrm{~mm}(P<0.001)$. CD-TLR occurred in 12 (18\%) of DCB-treated lesions versus 29 (43\%; $P=0.002)$ of PTA-treated lesions. Thirty-six planned minor amputations were performed, 17 in the DCB arm and 19 in the PTA arm. Only one major amputation occurred in the PTA group. At 12 months, mean ABIs in the DCB versus PTA groups were 0.78 versus $0.47(P<0.001)$; mean $\mathrm{RC}$ was 0.9 (DCB) and 2.0 (PTA; $P=0.004)$. Complete index ulcer healing, $86 \%$ (DCB) and 67\% (PTA; $P=0.01$ ), as well as average time to index ulcer healing, 4.4 months (DCB) and 5.2 months (PTA; $P=0.01$ ), were also significantly different (Table 4). With such findings, DEBATE-BTK appeared as a resounding attestation for DCB therapy in infrapopliteal disease. However, there are caveats that must be highlighted. More than any other study, DEBATE-BTK offered a postprocedure outpatient wound care clinic not often seen in the real world. Patients were seen twice a week for 2 months, then once a week for a month, and then biweekly thereafter. Undoubtedly, such rigorous wound care follow-up maximized the clinical benefit of intervention. This is supported by the equivalent rates of LS found in both DCB and PTA arms. Additionally, patients were enrolled only after successful wiring of the target vessel, and LS rates cannot be compared to studies designed on an intention-to-treat basis. Further, the study was unblinded. Despite these considerations, a statistical benefit was maintained between DCB- versus PTA-treated lesions and ultimately fueled larger prospective trials.

The IN.PACT Amphirion DCB was put to the test with the Drug-Eluting Balloon Versus Standard Balloon
Angioplasty of Infrapopliteal Arterial Revascularization in Critical Limb Ischemia (IN.PACT DEEP) trial. ${ }^{48}$ This was a prospective, multicenter, randomized-controlled trial with independent clinical event adjudication (blinded angiographic and wound core laboratories) that randomized 358 CLI patients 2:1 to DCB or PTA. The two co-primary efficacy end points were CD-TLR and LLL. The primary safety end point through 6 months was a composite of all-cause mortality, major amputation, and CD-TLR. All subjects were followed as a clinical cohort, and 167 subjects were studied in an angiographic cohort. Baseline patient, angiographic, and wound characteristics were well matched with a few exceptions (Table 3). The majority of patients were of RC 5 (84.1\% DCB and $77.3 \%$ PTA) with an average $\mathrm{ABI}$ of 0.75 and 0.81 , respectively. Impaired inflow was significantly higher in the DCB arm $(40.7 \%)$ versus the PTA $\operatorname{arm}(28.8 \% ; P=0.035)$. In contrast, target lesions were longer $(129 \pm 95 \mathrm{~mm}$ vs $102 \pm 91 \mathrm{~mm})$ in the PTA arm versus the DCB arm $(P=0.002)$. This held true in the 167-patient angiography cohort with mean lesion lengths of $59.1 \pm 41.7 \mathrm{~mm}$ and $79.7 \pm 74.6 \mathrm{~mm}(P=0.060)$ and total occlusion present in $31.6 \%$ and $32.7 \%(P=1.00)$ within the DCB versus PTA treatment arms, respectively. By core laboratory evaluation, wound area was comparable between the two groups but wound depth was significantly less in the DCB versus PTA arms $(0.8 \pm 1.3 \mathrm{~mm}$ vs $1.8 \pm 3.8 \mathrm{~mm} ; P=0.040)$. Professional wound care was received by $62.2 \%$ of DCB patients and $52.1 \%$ of PTA patients $(P=0.087)$. Regarding procedural characteristics, predilatation was performed in $90.5 \%$ of DCB-treated lesions and $36.0 \%$ of PTA-treated lesions $(P<0.001)$. Direct revascularization to the wound-related artery was performed in $35.6 \%$ of patients in the DCB arm and $43.7 \%$ of patients in the PTA arm $(P=0.166)$. Procedural complications in aggregate were significantly higher in the DCB arm (9.7\%) versus the PTA arm (3.4\%; $P=0.035)$. However, these complications were successfully managed and not associated with a higher incidence of distal embolization or need for provisional stent implantation. Of note, failure to obtain $<30 \%$ postprocedure residual stenosis constituted an exclusion criterion for either group. Ultimately, there was no significant difference in the 12-month primary efficacy end points of CD-TLR ( $11.9 \%$ vs $13.5 \%, P=0.682)$, LLL $(0.61 \pm 0.78 \mathrm{~mm}$ vs $0.62 \pm 0.78 \mathrm{~mm}, P=0.950)$, and BR $(41 \%$ vs $35.5 \%, P=0.609)$. The composites of all-cause death, major amputation, and CD-TLR rates through 6 months were $17.7 \%$ in the DCB arm and $15.8 \%$ in the PTA arm $(P=0.021$ for noninferiority) (Table 4). That said, a safety signal driven by major amputation at 12 months was observed with rates 
of $8.8 \%$ and $3.6 \%(P=0.080)$ in the DCB and PTA arms. The observed absence of superiority compared to PTA and the adverse safety signal resulted in the sponsor's decision to prematurely stop the study and withdraw the DCB device from the market. The IN.PACT DEEP trial illustrates the challenges posed by the CLI patient population and the caution needed in our interpretation of earlier, perhaps less rigorous DCB investigations. Nonetheless, the CD-TLR rate $(13.5 \%)$ and $\mathrm{BR}(35.5 \%)$ at 12 months for the PTA arm of this study represent an unprecedented benchmark that has not been seen in historical data. ${ }^{46,47}$ Further, guidelines regarding postoperative wound care and decision pathways to amputation were absent in this multicentered protocol introducing some level of variability. Some have postulated that the divergent findings of the IN.PACT Amphirion from that of the IN.PACT Admiral DCB designed for femoropopliteal use may lie in the design of the BTK balloon. ${ }^{49}$ First, the Amphirion was manually coated with the urea excipient and paclitaxel only after being folded, possibly resulting in nonuniform distribution and unprotected delivery, leaving the paclitaxel coating vulnerable to loss during transit. Further, the material used in the Amphirion when compared to the IN.PACT Admiral differs in its surface energy. A higher surface energy may provide less efficient paclitaxel release after inflation and contact with vessel endothelium. Problems such as these simply highlight the unknowns regarding this technology and the bioengineering variables that may influence the efficacious application of DCB therapy in CLI patients.

With the withdrawal of the Amphirion balloon, there have been new entrants in the BTK DCB market including Biotronik's Passeo-18 LUX drug-releasing PTA balloon catheter, which was compared to the uncoated Passeo-18 PTA balloon catheter in subjects requiring revascularization of infrapopliteal arteries (BIOLUX P-II trial). ${ }^{50}$ The Passeo-18 Lux DCB varies from the Medtronic Amphirion in that paclitaxel is incorporated into a delivery excipient of BTHC. This was a prospective, multicenter, randomized first-in-man study enrolling 72 patients who were randomized to either the Passeo-18 LUX DEB (Biotronik AG) or Passeo-18 PTA. Clinical follow-up was assessed at 1, 6, and 12 months with angiographic assessment at 6 months. An independent committee adjudicated adverse events, and an independent core laboratory assessed angiographic parameters. The primary safety end point was a composite of 30-day all-cause mortality, major amputation, target lesion thrombosis, and target vessel revascularization. The primary performance end point was 6-month target lesion primary patency (defined as $<50 \%$ restenosis). Secondary end points were numerous and included BR, LLL, TLR, target vessel revascularization, and MAE at 6 and 12 months and changes in RC. Baseline patient and lesion characteristics were statistically well matched (Table 3 ). Mean lesion lengths were $113.1 \pm 88.1 \mathrm{~mm}$ (DCB) and $115 \pm 86.9 \mathrm{~mm}$ (PTA). The DCB group had statistically less lesions without calcification than the PTA group $(55.9 \%$ vs $81.6 \% ; P=0.018)$. Inflow lesions were treated in $50 \%$ of the DCB and $30.6 \%$ of the PTA groups $(P=0.093)$. Predilation was performed in $87.5 \%$ of DCB lesions and $32.5 \%$ of PTA lesions $(P<0.001)$. The primary safety end point, MAE at 30 days, occurred in $0 \%$ of the patients in the DCB group versus $8.3 \%$ of the patients in the PTA group. At 12 months, $41.1 \%$ (DCB) versus $39.1 \%$ (PTA) of the patients experienced a MAE and 3.3\% versus $5.6 \%$ experienced a major amputation of the target extremity. The primary performance end point, lesion-based patency loss at 180 days, was observed in $17.1 \%$ of DCB lesions and $26.1 \%$ of PTA lesions ( $P=0.298$ ). At 12 months, lesion-based patency loss was seen in $50.8 \%$ of DCB lesions and $45.6 \%$ of PTA lesions $(P=0.908)$. TLR at 12 months was $30.1 \%$ and $30.6 \%$ in the DCB and PTA cohorts, respectively. Despite the loss of patency and high TLR rates at 12 months between DCB and PTA, LS rates were high (96.7\% vs 94.1\%) in both groups. Further, mean RC improved comparably between the two groups, from $4.5 \pm 0.9$ at baseline to $2.3 \pm 2.3$ at 6 months in the DCB arm and from $4.4 \pm 1.0$ to $2.7 \pm 2.4$ in the PTA arm (Table 4). This study establishes not only the Passeo-18 LUX DCB safety profile as comparable to PTA in CLI but also its noninferiority regarding primary angiographic and clinical end points. Given its relatively small size, it may have been underpowered to elucidate subtle advantages observed at 6-month follow-up. The study authors suggest that significantly greater baseline calcified DCB lesions may have played a role in reduced drug delivery and efficacy of the balloon. The BIOLUX P-II trial was a well-designed study but highlights some of the challenges facing DCB therapy in BTK intervention.

The enthusiasm surrounding above-the-knee DCB technologies is somewhat bated in the face of the blurry BTK outcomes. As we move forward with designs for future BTK DCBs and their study protocols to investigate efficacy, one of the primary hurdles will be establishing and differentiating concrete clinical end points from that of procedural and angiographic success. The field needs uniformity in study design. The two randomized controlled trials suggest that 12-month CD-TLR, wound healing, RC, and LS are not statistically different between DCB and standard PTA. It is the opinion 
of these authors that future studies should prioritize these clinical end points to help differentiate efficacy. At the same time, the pilot registry and DEBATE-BTK studies suggest that DCB-treated lesions may demonstrate shorter lesion length restenosis and occlusion upon follow-up angiography. This raises the question, are there lesion or vessel attributes, which lend themselves to superior DCB outcomes? If so, by which mechanism might a lesion be best modified to achieve these results? Is there a role for adjuvant atherectomy? These are difficult questions that we have only recently started to address with ongoing trials. Lastly, what bioengineering and mechanical improvements in balloon, immunomodulation, and excipient design can be made to improve the delivery of active drug to the focus of disease? Undoubtedly, the empirical-based application of DCB technology in CLI, though still in its infancy, remains achievable.

\section{Conclusion}

The introduction of DCB therapy for the treatment of both femoropopliteal and infrapopliteal PAD has already impacted the endovascular management of PAD patients. The ongoing evaluation of this technology including long-term outcomes to confirm durability as well as cost-effectiveness data will determine the role this technology plays going forward. Certainly, robust data in the femoropopliteal space comparing DCB to standard angioplasty are serving to supplant standard angioplasty as the definitive treatment. Stronger data at this stage are lacking on the comparison of DCB technology with BMSs and DESs in the femoropopliteal segment. In addition, further investigation is warranted on the effects of combining the various forms of atherectomy with DCB therapy.

On the other hand, somewhat early experience with DCB therapy in the infrapopliteal space has been limited by a lack of uniformity in study end points and studies lacking the power to determine differences in hard clinical end points such as LS rates. Adjuvant atherectomy in this vascular space also has an unclear role at this point. Finally, the introduction of novel drug-delivery excipients such as BTHC require further validation in larger randomized trials, and head-tohead trials of the currently approved DCB catheters are also warranted to move the field forward.

\section{Disclosure}

Ehtisham Mahmud serves on the Consulting and Speaker's Bureau for Abbott Vascular and Global Advisory Board and Speakers Bureau for Medtronic. Mitul Patel serves on the Consulting and Advisory Board for Avinger, Inc. The other authors report no conflicts of interest in this work.

\section{References}

1. Norgren L, Hiatt WR, Dormandy JA, et al; TASC II Working Group Inter-society consensus for the management of peripheral arterial disease. Int Angiol. 2007;26(2):81-157.

2. Laird JR, Jain A, Zeller T, et al. Nitinol stent implantation in the superficial femoral artery and proximal popliteal artery: twelve-month results from the complete SE multicenter trial. J Endovasc Ther. 2014;21(2):202-212.

3. Laird JR, Katzen BT, Scheinert D, et al; RESILIENT Investigators. Nitinol stent implantation versus balloon angioplasty for lesions in the superficial femoral artery and proximal popliteal artery: twelve-month results from the RESILIENT randomized trial. Circ Cardiovasc Interv. 2010;3(3):267-276.

4. Laird JR, Yeo KK. The treatment of femoropopliteal in-stent restenosis: back to the future. J Am Coll Cardiol. 2012;59(1):24-25.

5. Rocha-Singh KJ, Bosiers M, Schultz G, et al. A single stent strategy in patients with lifestyle limiting claudication: 3-year results from the Durability II trial. Catheter Cardiovasc Interv. 2015;86(1):164-170.

6. Sabeti S, Mlekusch W, Amighi J, Minar E, Schillinger M. Primary patency of long-segment self-expanding nitinol stents in the femoropopliteal arteries. J Endovasc Ther. 2005;12(1):6-12.

7. Sabeti S, Schillinger M, Amighi J, et al. Primary patency of femoropopliteal arteries treated with nitinol versus stainless steel selfexpanding stents: propensity score-adjusted analysis. Radiology. 2004;232(2):516-521

8. Schillinger M, Sabeti S, Loewe C, et al. Balloon angioplasty versus implantation of nitinol stents in the superficial femoral artery. $N$ Engl J Med. 2006;354(18):1879-1888.

9. Schlager O, Dick P, Sabeti S, et al. Long-segment SFA stenting - the dark sides: in-stent restenosis, clinical deterioration, and stent fractures. J Endovasc Ther. 2005;12(6):676-684.

10. Dormandy JA, Rutherford RB. Management of peripheral arterial disease (PAD). TASC Working Group. TransAtlantic Inter-Society Consensus (TASC). J Vasc Surg. 2000;31(1 pt 2):S1-S296.

11. Rocha-Singh KJ, Jaff MR, Crabtree TR, Bloch DA, Ansel G; VIVA Physicians, Inc. Performance goals and endpoint assessments for clinical trials of femoropopliteal bare nitinol stents in patients with symptomatic peripheral arterial disease. Catheter Cardiovasc Interv. 2007;69(6):910-919.

12. Schillinger M, Sabeti S, Dick P, et al. Sustained benefit at 2 years of primary femoropopliteal stenting compared with balloon angioplasty with optional stenting. Circulation. 2007;115(21):2745-2749.

13. Dake MD, Ansel GM, Jaff MR, et al. Sustained safety and effectiveness of paclitaxel-eluting stents for femoropopliteal lesions: 2-year follow-up from the Zilver PTX randomized and single-arm clinical studies. J Am Coll Cardiol. 2013;61(24):2417-2427.

14. Dake MD, Ansel GM, Jaff MR, et al. Paclitaxel-eluting stents show superiority to balloon angioplasty and bare metal stents in femoropopliteal disease: twelve-month Zilver PTX randomized study results. Circ Cardiovasc Interv. 2011;4(5):495-504.

15. Duda SH, Bosiers M, Lammer J, et al. Drug-eluting and bare nitinol stents for the treatment of atherosclerotic lesions in the superficial femoral artery: long-term results from the SIROCCO trial. J Endovasc Ther. 2006;13(6):701-710.

16. Duda SH, Bosiers M, Lammer J, et al. Sirolimus-eluting versus bare nitinol stent for obstructive superficial femoral artery disease: the SIROCCO II trial. J Vasc Interv Radiol. 2005;16(3):331-338.

17. Duda SH, Pusich B, Richter G, et al. Sirolimus-eluting stents for the treatment of obstructive superficial femoral artery disease: six-month results. Circulation. 2002;106(12):1505-1509.

18. Scheinert D, Scheinert S, Sax J, et al. Prevalence and clinical impact of stent fractures after femoropopliteal stenting. $\mathrm{J} \mathrm{Am} \mathrm{Coll} \mathrm{Cardiol.}$ 2005;45(2):312-315.

19. Klein AJ, Chen SJ, Messenger JC, et al. Quantitative assessment of the conformational change in the femoropopliteal artery with leg movement. Catheter Cardiovasc Interv. 2009;74(5):787-798. 
20. Speck U, Cremers B, Kelsch B, et al. Do pharmacokinetics explain persistent restenosis inhibition by a single dose of paclitaxel? Circ Cardiovasc Interv. 2012;5(3):392-400.

21. Abola MT, Bhatt DL, Duval S, et al; REACH Investigators. Fate of individuals with ischemic amputations in the REACH Registry: three-year cardiovascular and limb-related outcomes. Atherosclerosis. 2012;221(2):527-535.

22. Mahoney EM, Wang K, Keo HH, et al; Reduction of Atherothrombosis for Continued Health (REACH) Registry Investigators. Vascular hospitalization rates and costs in patients with peripheral artery disease in the United States. Circ Cardiovasc Qual Outcomes. 2010;3(6):642-651.

23. Peacock JM, Keo HH, Duval S, et al. The incidence and health economic burden of ischemic amputation in Minnesota, 2005-2008. Prev Chronic Dis. 2011;8(6):A141.

24. Tepe G, Zeller T, Albrecht T, et al. Local delivery of paclitaxel to inhibit restenosis during angioplasty of the leg. $N$ Engl $J$ Med. 2008;358(7):689-699

25. Tepe G, Schnorr B, Albrecht T, et al. Angioplasty of femoral-popliteal arteries with drug-coated balloons: 5-year follow-up of the THUNDER trial. JACC Cardiovasc Interv. 2015;8(1 pt A):102-108.

26. Werk M, Langner S, Reinkensmeier B, et al. Inhibition of restenosis in femoropopliteal arteries: paclitaxel-coated versus uncoated balloon: femoral paclitaxel randomized pilot trial. Circulation. 2008;118(13):1358-1365.

27. Scheinert D, Duda S, Zeller T, et al. The LEVANT I (Lutonix paclitaxelcoated balloon for the prevention of femoropopliteal restenosis) trial for femoropopliteal revascularization: first-in-human randomized trial of low-dose drug-coated balloon versus uncoated balloon angioplasty. JACC Cardiovasc Interv. 2014;7(1):10-19.

28. Rosenfield K, Metzger DC, Scheinert D. A paclitaxel-coated balloon for femoropopliteal artery disease. NEngl J Med. 2015;373(18):1785-1786.

29. Werk M, Albrecht T, Meyer DR, et al. Paclitaxel-coated balloons reduce restenosis after femoro-popliteal angioplasty: evidence from the randomized PACIFIER trial. Circ Cardiovasc Interv. 2012;5(6):831-840.

30. Bosiers M, Torsello G, Gissler HM, et al. Nitinol stent implantation in long superficial femoral artery lesions: 12-month results of the DURABILITY I study. J Endovasc Ther. 2009;16(3):261-269.

31. Liistro F, Grotti S, Porto I, et al. Drug-eluting balloon in peripheral intervention for the superficial femoral artery: the DEBATE-SFA randomized trial (drug eluting balloon in peripheral intervention for the superficial femoral artery). JACC Cardiovasc Interv. 2013;6(12):1295-1302.

32. Laird JR, Schneider PA, Tepe G, et al; IN.PACT SFA Trial Investigators. Sustained durability of treatment effect using a drug-coated balloon for femoropopliteal lesions: 24-month results of IN.PACT SFA. J Am Coll Cardiol. 2015;66(21):2329-2338.

33. Tepe G, Laird J, Schneider P, et al. Drug-coated balloon versus standard percutaneous transluminal angioplasty for the treatment of superficial femoral and popliteal peripheral artery disease: 12 -month results from the IN.PACT SFA randomized trial. Circulation. 2015;131(5):495-502.

34. Scheinert D, Schulte KL, Zeller T, Lammer J, Tepe G. Paclitaxelreleasing balloon in femoropopliteal lesions using a BTHC excipient: twelve-month results from the BIOLUX P-I randomized trial. $J$ Endovasc Ther. 2015;22(1):14-21.
35. Schroeder H, Meyer DR, Lux B, Ruecker F, Martorana M, Duda S. Two-year results of a low-dose drug-coated balloon for revascularization of the femoropopliteal artery: outcomes from the ILLUMENATE first-in-human study. Catheter Cardiovasc Interv. 2015;86(2):278-286.

36. Lepantalo M, Matzke S. Outcome of unreconstructed chronic critical leg ischaemia. Eur J Vasc Endovasc Surg. 1996;11(2):153-157.

37. Wolfe JH, Wyatt MG. Critical and subcritical ischaemia. Eur J Vasc Endovasc Surg. 1997;13(6):578-582.

38. Bertele V, Roncaglioni MC, Pangrazzi J, Terzian E, Tognoni EG. Clinical outcome and its predictors in 1560 patients with critical leg ischaemia. Chronic Critical Leg Ischaemia Group. Eur J Vasc Endovasc Surg. 1999;18(5):401-410.

39. Beckman JA, Creager MA. Critical limb ischemia and intermediate-term survival. JACC Cardiovasc Interv. 2014;7(12):1450-1452.

40. Soga $Y$, Iida $\mathrm{O}$, Takahara $\mathrm{M}$, et al. Two-year life expectancy in patients with critical limb ischemia. JACC Cardiovasc Interv. 2014;7(12):1444-1449.

41. Moxey PW, Brownrigg J, Kumar SS, et al. The BASIL survival prediction model in patients with peripheral arterial disease undergoing revascularization in a university hospital setting and comparison with the FINNVASC and modified PREVENT scores. $J$ Vasc Surg. 2013;57(1):1-7.

42. Schmidt A, Ulrich M, Winkler B, et al. Angiographic patency and clinical outcome after balloon-angioplasty for extensive infrapopliteal arterial disease. Catheter Cardiovasc Interv. 2010;76(7):1047-1054.

43. Fernandez N, McEnaney R, Marone LK, et al. Multilevel versus isolated endovascular tibial interventions for critical limb ischemia. JVasc Surg. 2011;54(3):722-729.

44. Soderstrom MI, Arvela EM, Korhonen M, et al. Infrapopliteal percutaneous transluminal angioplasty versus bypass surgery as first-line strategies in critical leg ischemia: a propensity score analysis. Ann Surg. 2010;252(5):765-773.

45. Spreen MI, Martens JM, Hansen BE, et al. Percutaneous transluminal angioplasty and drug-eluting stents for infrapopliteal lesions in critical limb ischemia (PADI) trial. Circ Cardiovasc Interv. 2016;9(2):e002376.

46. Schmidt A, Piorkowski M, Werner M, et al. First experience with drugeluting balloons in infrapopliteal arteries: restenosis rate and clinical outcome. J Am Coll Cardiol. 2011;58(11):1105-1109.

47. Liistro F, Porto I, Angioli P, et al. Drug-eluting balloon in peripheral intervention for below the knee angioplasty evaluation (DEBATE-BTK): a randomized trial in diabetic patients with critical limb ischemia. Circulation. 2013;128(6):615-621.

48. Zeller T, Baumgartner I, Scheinert D, et al. Drug-eluting balloon versus standard balloon angioplasty for infrapopliteal arterial revascularization in critical limb ischemia: 12-month results from the IN.PACT DEEP randomized trial. J Am Coll Cardiol. 2014;64(15):1568-1576.

49. Available from: http://vascularnews.com/the-in-pact-deep-trial-puttingthe-results-into-context/?s=in.pact+deep+trial. Accessed June 2, 2016.

50. Zeller T, Beschorner U, Pilger E, et al. Paclitaxel-coated balloon in infrapopliteal arteries: 12-month results from the BIOLUX P-II randomized trial (BIOTRONIK'S-first in man study of the Passeo-18 LUX drug releasing PTA balloon catheter vs. the uncoated Passeo-18 PTA balloon catheter in subjects requiring revascularization of infrapopliteal arteries). JACC Cardiovasc Interv. 2015;8(12):1614-1622.
Medical Devices: Evidence and Research

\section{Publish your work in this journal}

Medical Devices: Evidence and Research is an international, peerreviewed, open access journal that focuses on the evidence, technology, research, and expert opinion supporting the use and application of medical devices in the diagnosis, monitoring, treatment and management of clinical conditions and physiological processes. The identification of novel devices and optimal use of existing devices which will lead to improved clinical outcomes and more effective patient management and safety is a key feature. The manuscript management system is completely online and includes a quick and fair peer-review system. Visit http://www. dovepress.com/testimonials.php to read real quotes from authors. 